\title{
Prevalence of Urinary Tract Infection in HIV Patients on Antiretroviral Drugs in Jos Metropolis, Nigeria
}

\author{
Sheyin Zakka, 2, *, Olowolafe Christian Oluwatosin ${ }^{3}$, Essien Unyime Cosmas ${ }^{1}$, Shindang John ${ }^{1}$, \\ Ede Folashade Rebecca ${ }^{1}$, Bigwan Emmanuel Isa ${ }^{1}$ \\ ${ }^{1}$ Department of Medical Laboratory Science, University of Jos, Jos, Nigeria \\ ${ }^{2}$ School of Medicine and allied Health Sciences, University of The Gambia, Banjul, Gambia \\ ${ }^{3}$ Medical Laboratory department, State Specialist Hospital, Maiduguri, Nigeria
}

Email address:

sheyinzakka@gmail.com (S. Zakka)

${ }^{*}$ Corresponding author

\section{To cite this article:}

Sheyin Zakka, Olowolafe Christian Oluwatosin, Essien Unyime Cosmas, Shindang John, Ede Folashade Rebecca, Bigwan Emmanuel Isa. Prevalence of Urinary Tract Infection in HIV Patients on Antiretroviral Drugs in Jos Metropolis, Nigeria. World Journal of Public Health. Vol. 3, No. 2, 2018, pp. 57-60. doi: 10.11648/j.wjph.20180302.14

Received: May 28, 2018; Accepted: June 20, 2018; Published: July 6, 2018

\begin{abstract}
Prevalence of UTI in HIV patients is well documented in several studies across the world, but there is paucity of data as regards UTI in HIV patients in Jos metropolis, Nigeria. The study was designed to determine the prevalence of urinary tract infection in HIV positive patients in Jos metropolis and their antibiotic susceptibility pattern. Two hundred and twentyfive mid-stream urine samples were obtained from HIV patients. Samples were cultured on cysteine lactose electrolyte deficient (CLED) agar and blood agar. Gram staining and biochemical tests were carried out to identify the bacteria isolates. Sensitivity testing was performed on isolates using disc diffusion method. Of the $225 \mathrm{HIV}$ patients tested, 13(5.8\%) were positive for UTI of which males had 5(4.8\%) while the females had $8(6.6 \%)$. The study showed the presence of UTI in all age groups with the exception of age group $\geq 46 y$ rs. The low prevalence of urinary tract infection recorded in the present study is an indication of the efficacy of prophylaxis administered to HIV patients to prevent opportunistic infection.
\end{abstract}

Keywords: Urinary Tract Infection, HIV, Prevalence, Antibiotic Sensitivity Pattern, Inoculum, Gram Staining

\section{Introduction}

Urinary tract infection is one of the most common bacterial infections and the cause of morbidity and hospitalization in HIV positive individuals. Urinary tract infection is responsible for approximately $60.0 \%$ of opportunistic infections associated with AIDS. This represents a considerable health problem amongst HIV infected patients [1]. Several studies have shown that the prevalence and risk of urinary tract infection (UTI) among HIV infected patients may be significantly high in HIV infected patients mainly with $\mathrm{CD} 4$ cell counts $<200$ cells/ $\mu \mathrm{L}$ [2].

UTIs may be seen as complicated or uncomplicated [3]. A complicated UTI is that which occurs in a patient with an abnormal anatomical urinary tract [4], while uncomplicated UTI refers to the occurrence of bacterial infection in patients with normal structural and functional urinary tract [5].
Recent studies have demonstrated a broad range of microorganisms causing UTIs in HIV-infected patients, namely Escherichia. coli, Proteus spp, Enterobacter spp, Klebsiella spp, Pseudomonas aeruginosa, Enterococcus faecalis, Staphylococcus aureus and rarely Candida spp., Salmonella spp., Acinetobacter spp., and Cytomegalovirus. [2]. Almost all the causative organisms of bacterial UTIs originate from faecal materials or the periurethral environment [6].

Varieties of antibiotics are available for the treatment of UTI. The choice of antibiotic depends on the severity of infection. The emergence of antibiotic resistance has posed a serious problem in the management of UTIs. However, such resistance may be due to extensive use and misuse of antimicrobial drugs which is a common norm in the management of UTIs $[7,8]$.

The prevalence of UTI among HIV patients is well documented in several studies across the world including 
Nigeria, but there is paucity of data as regards UTI in HIV patients in Jos metropolis. This study was set out to determine the prevalence of urinary tract infection among HIV positive individuals.

\section{Materials and Methods}

\subsection{Study Area}

The study was carried out in AIDS Prevention Initiative Nigeria (APIN) and Faith Alive Foundation located in Jos metropolis. Jos covers an area of $26,890 \mathrm{~km}^{2}$, and is located in the Middle Belt zone. Based on the 2006 population census figures, Jos had an estimated population of 900,000 residents. Jos has an elevation of 1,238 meters high above sea level [2].

\subsection{Study Population}

The study population included HIV positive males and females of all age groups on antiretroviral drugs attending AIDS Prevention Initiative Nigeria (APIN) and Faith Alive Foundation.

\subsection{Sample Size}

The sample size was determined using the equation for sample size according to Thrusfield [9].

\subsection{Ethical Consideration}

The ethical clearance for this research was sought and obtained from the ethical clearance committees of Jos University Teaching Hospital and Faith Alive Foundation before the commencement of the study. A written consent was obtained from subjects before collection of samples.

\subsection{Data Collection}

Information regarding patients age, sex, marital status, and occupation were obtained using a structured questionnaire.

\subsection{Specimen Collection}

Mid-Stream urine specimens were collected from 225 study participants in sterile screw capped labeled universal bottle. These were transported immediately on ice packs in a cooler to the Department of Medical Laboratory Science, University of Jos for processing.

\subsection{Sample Processing and Culture}

A Loop full of well mixed uncentrifuged urine was streak inoculated on the surface of blood agar and Cysteine Lactose Electrolyte Deficient (CLED) agar. The plates were incubated aerobically at $37^{\circ} \mathrm{C}$ for 24 hours after which the growth on the culture plates were examined by their colonial morphology and Gram staining. The isolates were further identified using the following biochemical tests: Indole test, citrate utilization test, oxidase test, urease test, catalase test and coagulase test.

\subsection{Antibiotic Susceptibility Testing}

Antibiotic susceptibility testing was performed by disc diffusion method. Pure colonies from culture plates were suspended in a sterile normal saline and were agitated to achieve a homogenous suspension. The suspension density was adjusted to 0.5 McFarland's standard [10]. The standardized inoculum was inoculated on the dried surface of Mueller Hinton agar plate using a sterile cotton swab and the surface of the plate was allowed to dry. Using a sterile forceps, the antibiotic impregnated discs were placed on the surface of the agar plate and were incubated aerobically at $37^{\circ} \mathrm{C}$ for $24 \mathrm{hrs}$. After overnight incubation, the zone diameters were measured and the results were noted according to Clinical and Laboratory Standards institute [11] interpretative break point.

The antibiotic agents used in this study includes; ciprofloxacin $(10 \mu \mathrm{g})$, gentamicin $(10 \mu \mathrm{g})$, erythromycin $(30 \mu \mathrm{g})$, levofloxacin $(20 \mu \mathrm{g})$, chloramphenicol $(30 \mu \mathrm{g})$, ampiclox $(20 \mu \mathrm{g})$, streptomycin $(30 \mu \mathrm{g})$, amoxicillin $(20 \mu \mathrm{g})$, norfloxacin $(10 \mu \mathrm{g})$, rifampicin $(20 \mu \mathrm{g})$.

\subsection{Data Analysis}

The statistical analysis was done using statistical package for social sciences (SPSS) Version 21. The statistical significance was considered at $\mathrm{p}<0.05$.

\section{Results}

Out of the 225 urine specimens examined, 13 (5.8\%) were positive for UTI. Females had the highest occurrence of UTI $8(6.6 \%)$ compared to the male counterparts $5(4.8 \%)$ as shown in Table 1. The age group 16-30years recorded the highest prevalence of UTI $3(8.1 \%)$, followed by $\leq 15$ years with $1(7.7 \%)$ and 31-45years age group had the least occurrence $9(6.9 \%)$ and regarding marital status, the highest prevalence was observed among the singles $4(6.6 \%)$, while the married had a prevalence of $9(5.8 \%)$ as shown in Table 1 . The prevalence of UTI in relation to occupation indicated that the unemployed had the highest prevalence of 3(9.1\%), followed by business owners $8(7.0 \%)$ and civil servants $2(3.2 \%)$ as shown in Table 1 .

Table 2: The antibiotic sensitivity pattern of bacteria isolates indicates that Levofloxacin 11(84.6\%) exhibit the highest activity against bacteria isolates, and Escherichia coli showed the highest sensitivity to Levofloxacin 5(100\%). The distribution of uropathogens from urine specimens of HIV positive patients revealed Escherichia coli as the most prevalent uropathogens 5(38.5\%), followed by Staphylococcus aureus 3(23.1\%), Klebsiella species $3(23.1 \%)$, while the least occurring pathogens were Proteus species and Pseudomonas aeruginosa had $1(7.7 \%)$ as shown in Figure 1. 
Table 1. Demographic characteristics of patients examined.

\begin{tabular}{llcc}
\hline Demographic variables & Frequency $\mathbf{~}=\mathbf{2 2 5}$ & No. positive (\%) & P-value \\
\hline Gender & & & \\
Male & 104 & $5(4.8)$ & 0.563 \\
Female & 121 & $8(6.6)$ & \\
Age (years) & & & \\
$\leq 15$ & 13 & $3(7.7)$ & 0.314 \\
$16-30$ & 37 & $9(6.1)$ & \\
$31-45$ & 131 & $0(0.0)$ & 0.760 \\
$\geq 46$ & 44 & $4(6.6)$ & \\
Marital status & & $9(5.5)$ & \\
Single & 61 & & \\
Married & 164 & $2(3.2)$ & \\
Occupation & & $0(0.0)$ & \\
Civil servants & 62 & $8(7.0)$ & \\
Farmer & 15 & $3(9.1)$ & \\
Business & 115 & 33 & \\
None & &
\end{tabular}

Table 2. Antibiotic sensitivity pattern of bacteria isolates from urine specimens of HIV positive patients attending APIN and Faith Alive foundation in Jos.

\begin{tabular}{llllllllllll}
\hline Bacteria isolates & No isolated & AMX & NB & S & CH & CPX & E & LEV & CN & APX & RD \\
\hline E. coli & 5 & $2(40.0)$ & $1(20.0)$ & $1(20.0)$ & $3(60.0)$ & $3(60.0)$ & $2(40.0)$ & $5(100.0)$ & $2(40.0)$ & $4(80.0)$ & $3(60.0)$ \\
S. aureus & $30(0.0)$ & $0(0.0)$ & $1(33.3)$ & $1(33.3)$ & $1(33.3)$ & $2(66.7)$ & $2(66.7)$ & $3(100.0)$ & $2(66.7)$ & $0(0.0)$ & \\
Klebsiella spp & 3 & $0(0.0)$ & $0(0.0)$ & $2(66.7)$ & $2(66.7)$ & $3(100.0)$ & $3(100.0)$ & $2(66.7)$ & $1(33.3)$ & $1(33.3)$ & $0(0.0)$ \\
P. aeruginosa 1 & $0(0.0)$ & $1(100.0)$ & $1(100.0)$ & $0(0.0)$ & $0(0.0)$ & $0(0.0)$ & $1(100.0)$ & $0(0.0)$ & $0(0.0)$ & $0(0.0)$ & \\
Proteus spp.10(0.0) & $0(0.0)$ & $1(100.0)$ & $0(0.0)$ & $1(100.0)$ & $0(0.0)$ & $1(100.0)$ & $1(100.0)$ & $0(0.0)$ & $0(0.0)$ & & \\
Total & $132(15.4)$ & $2(15.4)$ & $6(46.2)$ & $6(46.2)$ & $8(61.5)$ & $7(53.8)$ & $11(84.6)$ & $7(53.8)$ & $7(53.8)$ & $3(23.1)$ & \\
\hline
\end{tabular}

Key: AMX- Amoxicillin, NB-Norfloxacin, S-Streptomycin, CH-Chloramphenicol, CPX-Ciprofloxacin, E-Erythromycin, LEV-Levofloxacin, CN-Gentamicin, APX-Ampiclox, RD-Rifampicin

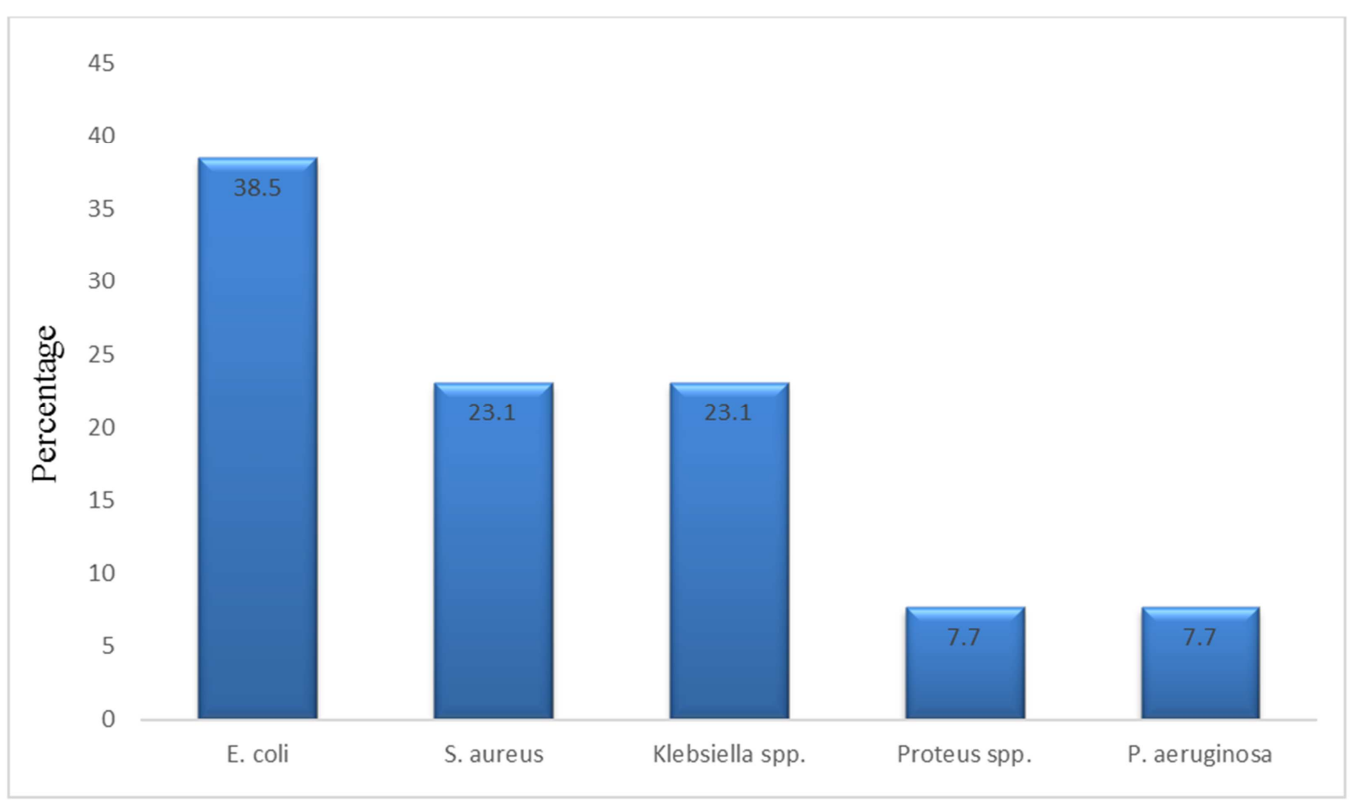

Figure 1. Distribution of bacteria isolates from specimens of HIV positive patients attending APIN and Faith Alive foundation in Jos.

\section{Discussion}

The study revealed $5.8 \%$ prevalence of uropathogens in tandem with results of similar study obtained elsewhere [2, 12-13]. There have been several studies on this subject and it is expected that the stakeholders involved in management of HIV positive individuals have utilized the result emanating from previous study, hence the low prevalence observed in this study. It may also be as result of the routine use of cotrimoxazole as a prophylaxis for the prevention of opportunistic infection among HIV positive individuals.

This study also observed that the prevalence of UTI in females $6.6 \%$ was higher compared to $4.8 \%$ in males, the reason for this higher prevalence observed in females could be attributed to any of the following; proximity of female genitalia to the anal region, the short and wider urethra of females and sexual intercourse [1, 14-16].

There was no statistical significant difference in the 
occurrence of UTI in relation gender $(\mathrm{P}=0.563)$, age group $(\mathrm{P}=0.314)$, marital status $(\mathrm{P}=0.760)$ and occupation $(\mathrm{P}=0.454)$ of individual examined, and this is contrary to observations by Kanuet al. [17] but it agrees with UTI study carried out by Essien et al.[18].

Escherichia coli was the most predominant pathogen with a prevalence of $38.5 \%$. This is in line with similar reports from previous studies [1, 12, 18-20].

In terms of sensitivity pattern, Levofloxacin $(84.6 \%)$ had the highest overall sensitivity followed by Ciprofloxacin $(61.5 \%)$, while the least sensitivity was shown by Amoxicillin (15.4\%), and Norfloxacin (15.4\%). The variation in sensitivity pattern of the isolates might be due to the irrational prophylactic usage and an inappropriate dosing schedule.

\section{Conclusion}

The $5.8 \%$ prevalence in this study has established that UTI is present in HIV positive patients. Escherichia coli were the most prevalent uropathogens isolated. Levofloxacin showed the highest activity against bacteria isolates tested. There is no gain saying that our finding has added to the already existing information on UTI in HIV positive patients in Jos, Nigeria.

\section{References}

[1] Samuel S. O., Salami T. A. T., Adewuyi G. M., Babatope E., Ekozien M. I. Prevalence of Urinary Tract Infections among a cohort of HIV Positive Patients accessing care in a rural health centre in Nigeria. Journal of Microbiology and Biotechnology Research 2012; 2(4):507-510.

[2] Bigwan E. I., Wakjissa F. D. Prevalence of Urinary Tract Infections among HIV patients attending a Non Governmental Health Facility in Jos, Plateau State, Nigeria. International Journal of Biomedical and Advanced Research 2013; 4(8): 528-533.

[3] Jancel T. and Dudas V. Management of uncomplicated urinary tract infection. Western Journal of Medicine 2002; 176(1): 5660 .

[4] Neal D. Complicated Urinary Tract Infection. Urology Clinic North America 2008 35(1):13-22.

[5] Shawn D., Jeypandy T. D and Anil K. Guidelines for the diagnosis and Management of recurrent. Urinary tract infection in women. Canadian Urological Association 2011; 48(4): 235-255.

[6] Ieriebor B. C., Obi C. L., Akinyemi O., Ramalivhana N. J., Hatton T., and Okoh A. I. Africa Uropathogens isolated from HIV-infected patients from Limpopo Province, South African Journal of Biotechnology 2012; 11(46):10598- 10604.

[7] Okon K. O., Askira U., Isyakatab M., Gliamba P. E., Jibrin Y. B., Hamidu I. M., Kank O. P., Aguro C. U. A 5years Retrospective Analysis of Urinary Bacterial Pathogen and Their Antimicrobial Sensitivity Pattern in a Tertiary Hospital in
Maiduguri, Nigeria. Journal of Medical Research 2014; 6(6):56.

[8] WHO. 2015. WHO, UNAIDS and UNICEF, "Global HIV/AIDS response: Epidemic update and health sector progress towards universal access progress report 2011. Available at

http://www.unaids.org/en/media/unaids/contentassets/docume nts/naidspublication/2011/20111130 ua report en.pdf. Accessed on 12/4/2016.

[9] Thrusfield, M. V. Veterinary epidemiology. Blackwell Science Ltd, Cambridge 1997: 483.

[10] Mcfarland J. Nephelometer: an instrument for estimating the number of bacteria in suspensions used for calculating the opsonic index and for vaccines. Journal of the American Medical Association 1907; 14(5): 1176-1178.

[11] CLSI. Performance standards for antimicrobial susceptibility testing; Twenty- fourth Informational Supplement. Clinical and Laboratory Standards Institute document M2-A9, Wayne, PA, and USA2014: M100-S24.

[12] Jombo G. T., Egah D. Z., Ayeni J. A.. Bacteriology of urinary tractinfection among patients with acquired immunodeficiency syndrome in Jos, Nigeria. Nigeria Journal of Medicine2005; 14(4): 422-424.

[13] Ibadin O. M., Onunu A., and Ukoh G. M. Urinary tract infection in adolescence /Young adult Nigerians with Acquired Human Immuno deficiency Disease. A peerreview;Journal of Biomedical Science2006; 5(3):55-60.

[14] Omoregie R., and Eghafona N. O. Urinary tract infection among asymptomatic HIV patients in Benin City, Nigeria. British Journal of Biomedical Science2009; 66 (4): 190-193.

[15] Najar M. S., Saldanha C. L., Banday K. A. Approach to urinary tract infections. Indian Journal of Nephrology 2009; 19(4): 129-139.

[16] Essien U. C., Iheukwumere C. C., Davou G. I., Sheyin Z., Okolie C. E., Ede F. R., Ekwempu A. I. Prevalence and Predictors of Asymptomatic Urinary Tract Infectionamong HIV Positive Patients in Jos, North Central Nigeria. International Journal of Current Microbiology and Applied Sciences 2015; 4(9): 454-462.

[17] Kanu A. M., Mgbajiaka N., Abadom N.. Prevalence of urinary tract infection among HIVpatients in Aba, Nigeria. International Journal of Infectious Diseases2016; 45: 1-477.

[18] Essien U. C., Ede F. R., Idoko E., Vem T. S., Damen J. G., Sheyin Z. Bacteriology of Urinary Tract Infection Among Inmates in Jos Main Prison, Plateau State, Nigeria. European Journal of Pharmaceutical and Medical Research 2017;4(2): 179-182.

[19] Awolude O. A., Adesina O. A., Oladokun A., Mutiu W. B., Adewole I. F. Asymptomatic bacteriuria among HIV positive pregnant women. Journal of Virulence2010; 1(3):130-133.

[20] Alemu Agersew, Mulat Dagnew, Meseret Alem and Mucheye Gizachew. Uropathogeenic Bacter ial Isolates and their Antimicrobial Susceptibility Patterns among HIV/AIDS Patients Attending Gondar University Specialized Hospital Gondar, Northwest Ethiopia. Journal of Microbiology Research and Review 2013; 1(4): 42-51. 